\title{
Variations in the Effects Caused by Magnetic Field on Chlorophyll, Nitrogen, Calcium, and Iron Contents in Species of Vegetable Plants
}

\author{
Olusegun O. Alabi ${ }^{1 *}$, Samuel O. Sedara ${ }^{2}$, Kafayat Adeyemi ${ }^{1}$, Felix Oladejo ${ }^{1}$, Mutiu A. \\ Fakunle $^{1}$ and Funmilayo Ayedun ${ }^{3}$ \\ ${ }^{1}$ Department of Physics, Osun State University, Osogbo, Nigeria \\ ${ }^{2 *}$ Department of Physics and Electronics, Adekunle Ajasin University, Akungba-Akoko, \\ Ondo State \\ ${ }^{3}$ Physics Unit, Faculty of Science, National Open University of Nigeria \\ *Corresponding author, e-mail: olusegun.alabi@uniosun.edu.ng \\ Co-authors' e-mail addresses: samuel.sedara@aaua.edu.ng; kadeyemi@gmail.com; \\ felix.oladejo@uniosun.edu.ng; mutiu.fakunle@uniosun.edu.ng; \\ funmilayo.ayedun@noun.edu.ng \\ Received 3 Apr 2021, Revised 30 May 2021, Accepted 31 May 2021, Published May 2021 \\ DOI: https://dx.doi.org/10.4314/tjs.v47i2.38
}

\begin{abstract}
The rates of reduction in chlorophyll and nutrients such as nitrogen, calcium and iron with the distance or range of source of Magnetic Field (MF) had not been considered. In this work, patterns of damage or reduction caused by a magnetic field on two different species of vegetables were studied. The first group was planted in an environment without the influence of MF, while the second group was subjected to high MF under the $330 \mathrm{kV}$ electric lines. The magnetometer was used to measure the MF intensities. The chlorophyll content of each vegetable sample was determined on the field with a portable chlorophyll meter. The dried harvested samples of two different vegetable species were analyzed using an Atomic Absorption Spectrophotometer (AAS) to assess the concentrations of nitrogen $(\mathrm{N})$, calcium $(\mathrm{Ca})$, and iron $(\mathrm{Fe})$ in the samples. Results of elemental concentrations were subjected to statistical analysis to appraise the relationships between the measured variables as responses to high MF. It was observed that the effects of high MF are stronger on spinach vegetable than Lagos spinach. This suggested that the effects of MF on plants are not only MF intensity dependent, but also species-dependent.
\end{abstract}

Keywords: Magnetic field, Exposure, Regression analysis, Power transmission, Chlorophyll, Iron.

\section{Introduction}

Blackman and co-workers used high voltage gradients of $20-40 \mathrm{kV} / \mathrm{m}$ and were found to be injurious to plants (Blackman 1924). This implies that the exposure of plants to Electric or Magnetic Field (MF or EF) could have either positive or negative effects, but this depends on the strength of the MFs. According to previous studies, the strengths of the geomagnetic field range from 0.1 to $0.21 \mathrm{nT}$ (Nyakane et al. 2019, Oladejo et al. 2020) It was observed that plants growing close to a low magnetic field (LMF) such as antenna showed normal vegetative patterns, but plants near high voltage transmission lines growth were adversely affected (Hart and Marino 1977).

Some studies that have been carried out in this field were to investigate the plants' growth in the absence of the Earth's magnetic field (Negishi et al. 1999). Some scientists worked on the impact of extremely strong magnetic 
fields (Tanasković et al. 2012), while some worked on applications of alternating low magnetic field (LMF). However, it was observed that the effects of the MF on plants may be dependent on the species of the plant and the intensity of the MF. Also, it was observed that the studies of the effects of electromagnetic radiation on photosynthesis have been few and mainly focused on phenotypic level (Negishi et al. 1999, Tanasković et al. 2012). Information on the effects of MF on the chlorophyll contents of the plants, which is a fundamental factor in photosynthesis, was lacking.

In this work, we studied the effects of plant exposure to high voltage EMF from transmission lines on the chlorophyll contents of two (2) different species of vegetable plants in order to determine the patterns of effects of MF on different species of vegetables. According to Muthuchelian et al. (1989), EMF is the combination of an electric field and a magnetic field. An electric field is produced by stationary charges and a magnetic field by moving charges or current. The magnetic field can pass through most materials; while electric fields are usually shields by objects. These changes occur not only in the tissues directly exposed, but also systemically in distant tissues (Negishi et al. 1999, Tanasković et al. 2012, Muthuchelian et al. 1989). While the long-term impacts of these metabolic changes remain largely unknown, we propose to consider nonionizing HF-EMF radiation as a non-injurious, genuine environmental factor that readily evokes changes in plant metabolism. Also the potential of Celosia species in alleviating micronutrient deficiencies and prevention of diet-related chronic diseases have been studied previously by some scientists (Muthuchelian et al. 1989, Vian et al. 2016, Adegbaju et al. 2019).

In this study, we assessed the patterns of damages or reductions caused by electromagnetic fields on two different species of vegetables as a result of variations in electromagnetic field strengths (or distance) from the sources.
The study considered the selected crops, that is, Amaranthus (Amaranthus cruentus) and spinach (Celosia argentea), also known as Lagos spinach, planted within the Osun State University, Osogbo, Osun State, Nigeria. However, there were some limitations in the study which are the range of the electromagnetic field exposure and the height of the platform where the crops were planted. Also, is the relationship between the rate of reduction in growth and biochemical characteristics of the plants and the distance (or range) of the source of the electromagnetic field.

This work was intended to determine the patterns of the damages or reductions caused by EMF on the selected plants at different MF strengths (or distances) from the sources of the EMF. To achieve this, we evaluated the yield responses of selected vegetable crops exposed to EMF produced under power lines and ascertained the health implications of consuming vegetable crops harvested from under the power lines.

Moving electric charges (or currents) produce a magnetic field. It is measured in Tesla (T). Magnetic field strength or intensity is inversely proportional to the square of the distance from the source. This implies that MF decreases as the distance from the source decreases. Magnetic field strength is measured in Ampere per meter $(\mathrm{A} / \mathrm{m})$. It can also be defined as a quantitative measure of strength or the weakness of the magnetic field (Reynolds 1997).

According to Faraday MF, (B) is given as:

$$
B=\mu I / 2
$$

where $B=$ magnetic field magnitude (Tesla, T); $I=$ magnitude of the electric current (Ampere, A); $r=$ distance from the source (m); $\mu=$ permeability of free space.

The relationship between magnetic field (B) and magnetic field strength $(\mathrm{H})$ is given as:

$$
\mathrm{B}=\mu \mathrm{H}
$$

where; $\mathrm{B}=$ magnetic field magnitude; $\mu=$ absolute permeability of the medium in vacuum; and $\mathrm{H}=$ magnetic field strength. 


\section{Materials and Methods \\ Determination of magnetic field intensities}

The experimental materials comprised of amaranth spinach (Amaranthus cruentus) and Lagos spinach (Celosia argentea) which were divided into two groups and treated as follows: The first group was planted in an environment without any MF's influence, while the second group was subjected to high MF under the 330 $\mathrm{kV}$ electric lines. The seeds were sown and the experimental plot of each spacing between the rows was approximately $0.1 \mathrm{~m}$, after the plants were ripped after 30 days, then magnetometer model; GSM-8, serial number: 6716522 (GEM system) was used to measure the MF intensities.

\section{Determination of chlorophyll content}

To determine the chlorophyll content, a portable chlorophyll meter; CM-8 (serial number TP201933112103) was used on the field on the harvested vegetables (Figure 1 and Figure 2).

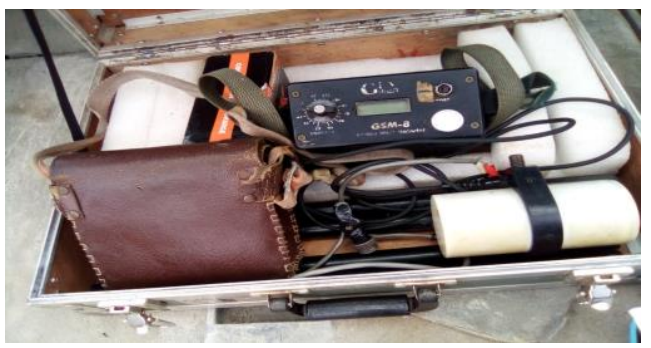

Figure 1: The magnetometer model; GSM-8, serial number: 6716522; GEM system.

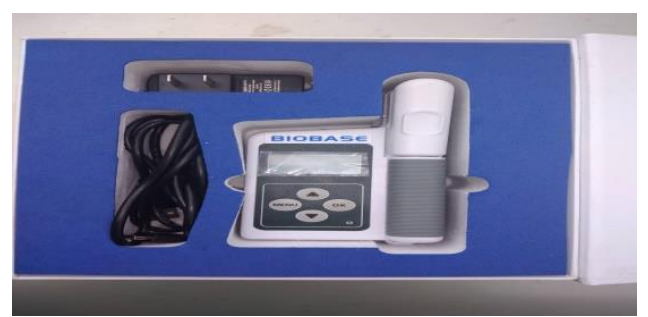

Figure 2: Portable chlorophyll meter, product model; CM-8, serial number: TP201933112103 Electric supply; 220V 50MZ.

\section{Digestion of materials}

The digestion of vegetable leaves for elemental analysis using Atomic Absorption Spectrophotometry (AAS). Two grams ( $2 \mathrm{~g}$ ) of each vegetable sample was weighed using digital analytical meter balance with four decimal point range into a $100 \mathrm{ml}$ crucible. The sample in the crucible was then transferred into a muffle furnace and the temperature set to 550 ${ }^{\circ} \mathrm{C}$ for 4 hours. After 4 hours, the samples were brought out from the furnace and $3 \mathrm{ml}$ of concentrated nitric acid $\left(\mathrm{HNO}_{3}\right)$ was added followed by $2 \mathrm{ml}$ of concentrated hydrochloric acid $(\mathrm{HCl})$, then $80 \mathrm{ml}$ of distilled water, and the solution was placed on a hot plate for digestion. After digestion had been completed, the samples were allowed to cool, filtered into $100 \mathrm{ml}$ standard flasks. The filtrates were then transferred into $120 \mathrm{ml}$ AAS bottles, and the samples were ready for elemental analysis using Atomic Absorption Spectrometry (AAS). To determine the contents of minerals and trace elements, the material was grounded to a fine powder in the laboratory, and measurement of the levels of nitrogen $(\mathrm{N})$, calcium $(\mathrm{Ca})$, and iron $(\mathrm{Fe})$ were recorded using the flame AAS technique.

After analyzing the chlorophyll content for each plant, the percentage of decrease in chlorophyll content was determined by comparing the chlorophyll content of each plant at different levels of MF intensities with the chlorophyll contents of control plants. These were calculated using Equation (3), and the reduction in chlorophyll content was measured in percentage. This was done in turn for nitrogen $(\mathrm{N})$, calcium $(\mathrm{Ca})$, and iron $(\mathrm{Fe})$ for the two vegetable plants at different intensities.

\section{Determination of damage or reduction}

The changes in the levels of damages or reductions caused as a result of exposure to the magnetic field, the content at each level of exposure were compared with the contents of the parameters of the control experiment which were determined using Equation 3. 
Alabi et al. - Variations in the effects caused by magnetic field on chlorophyll, nitrogen, ...

$$
D C=\frac{P C C P-P C E P}{P C C P} \times 100
$$

Where; $\mathrm{DC}=$ Percentage of damage/decrease in content; $\mathrm{PCCP}=$ Percentage of content in control plant; and PCEP = Percentage of content in exposed plant.

\section{Data analysis}

Correlation coefficients between the magnetic field, chlorophyll contents, and the concentrations of nutrients $\mathrm{N}, \mathrm{Ca}$, and $\mathrm{Fe}$ in two different species of vegetables as a function of the magnetic field were calculated to ascertain the connectivity between the variables by Statistical Package for Social Sciences (SPSS) software.

\section{Results and Discussion}

The results obtained in the research on the effects of EMF on the two different species of vegetable plants are presented in Table 1 . The first column shows the two spices of the vegetables used in the experiment. The vegetable plants were Lagos spinach (LS) and spinach (S). The second column of the table presents an overview of various magnetic field intensities that were used and these indicate the levels of the specific intensity of the MF.

Table 1: Effects of MF on chlorophyll, N, Ca, and Fe of vegetable plants

\begin{tabular}{|c|c|c|c|c|c|c|c|c|c|c|}
\hline SN & Species & $\begin{array}{l}\text { MF } \\
(\boldsymbol{\mu T})\end{array}$ & $\begin{array}{l}\text { CHL } \\
(\%)\end{array}$ & $\begin{array}{l}\text { Damage } \\
\text { CHL } \\
(\%)\end{array}$ & $\begin{array}{l}\mathrm{N} \\
(\%)\end{array}$ & $\begin{array}{l}\text { Damage/ } \\
\text { Decrease } \\
\mathbf{N} \\
(\%)\end{array}$ & $\begin{array}{l}\mathrm{Ca} \\
(\%)\end{array}$ & $\begin{array}{l}\text { Damage/ } \\
\text { Decrease } \\
\text { Ca }(\%)\end{array}$ & $\begin{array}{l}\mathrm{Fe} \\
(\%)\end{array}$ & $\begin{array}{l}\text { Damage/ } \\
\text { Decrease } \\
\text { Fe }(\%)\end{array}$ \\
\hline 1 & $\mathrm{LS}$ & 30714 & 30.5 & 23.94 & 2.9363 & 5.91 & 0.4136 & 33.77 & 30.1864 & 29.31 \\
\hline 2 & LS & 31187 & 28.7 & 28.43 & 2.4194 & 22.47 & 0.3772 & 39.6 & 25.0666 & 41.29 \\
\hline 3 & LS & 32259 & 27.79 & 30.57 & 2.0262 & 35.07 & 0.3001 & 51.95 & 21.4424 & 49.78 \\
\hline 4 & LS & 32497 & 25.6 & 36.16 & 1.6468 & 47.23 & 0.2269 & 63.67 & 15.3729 & 64 \\
\hline 5 & $\begin{array}{l}\mathrm{LS} \\
\mathrm{LS}\end{array}$ & 32548 & 22.4 & 44.14 & 0.9691 & 68.95 & 0.1618 & 74.09 & 10.2963 & 75.89 \\
\hline 6 & (Control) & 45 & 40.1 & 0 & 3.1206 & 0 & 0.6245 & 0 & 42.7 & 0 \\
\hline 7 & $\mathrm{~S}$ & 30714 & 2.9 & 28.39 & 1.8227 & 30.66 & 0.2843 & 28.64 & 22.1847 & 29.33 \\
\hline 8 & $\mathrm{~S}$ & 31187 & 2.2 & 42.3 & 1.3352 & 49.29 & 0.227 & 44.1 & 17.7285 & 43.53 \\
\hline 9 & $\mathrm{~S}$ & 32259 & 1.9 & 50.13 & 1 & 61.96 & 0.1925 & 51.68 & 12.8115 & 59.19 \\
\hline 10 & $\mathrm{~S}$ & 32497 & 1.6 & 58 & 0.8118 & 69.12 & 0.1453 & 63.53 & 10.3332 & 67.08 \\
\hline 11 & $\begin{array}{l}S \\
S\end{array}$ & 32548 & 1 & 73.75 & 0.5656 & 78.48 & 0.1001 & 74.87 & 7.7573 & 75.29 \\
\hline 12 & (Control) & 45 & 3.81 & 0 & 2.6288 & 0 & 0.3984 & 0 & 31.393 & 0 \\
\hline
\end{tabular}

To investigate how significant were the changes in the levels of damages or other effects caused as a result of exposure to the magnetic field, the content at each level of exposure was compared with the content of the parameters of the control experiment. These were determined by Equation 3. The fifth, seventh, ninth, and eleventh columns of Table 1 present the levels of damages (or decrease) of chlorophyll, nitrogen $(\mathrm{N})$, calcium $(\mathrm{Ca})$, and iron $(\mathrm{Fe})$ respectively, as a result of the effects of the MF on plants at different intensities. The results of the study indicated that there is a strong direct relationship between MF intensities and the levels (or amount) of damages on chlorophyll (Chl), nitrogen $(\mathrm{N})$, calcium $(\mathrm{Ca})$, and iron $(\mathrm{Fe})$ as a result of the effects of the MF on plants This implies that the levels of damages or reduction increase with increase in MF strengths. It is recorded that the biological effects of MF and EMF exposure depend on the strength. This observation corroborates with previous studies, but in the present study, the actual levels of 
damage or reduction caused by different strengths of MF were determined for each parameter. It was further observed that the effects of MF are stronger on spinach than Lagos spinach. This indicates that the effects are species-dependent. The present study corroborates with the results of previous studies, however, it was further observed in the present study that the effects are speciesdependent. Chlorophyll is an important factor in the photosynthesis process, which is very vital for food production in plants' production and growth. This work showed the levels of damages caused at different intensities of MF and also showed that the damages depend on the species of the vegetable plants. This information provided from the preset study was lacking in the previous studies and they are vital for both environmental and human health protection.

\section{Correlation coefficient analysis}

The individual concentrations of nutrients $\mathrm{N}, \mathrm{Ca}$, and $\mathrm{Fe}$ along with chlorophyll contents in the vegetables can be affected by the intensity of the magnetic field (MF). Correlation coefficients between the magnetic field, chlorophyll contents, and the concentrations of nutrients $\mathrm{N}, \mathrm{Ca}$, and $\mathrm{Fe}$ in two different species of vegetables as a function of the magnetic field calculated to ascertain the connectivity between the variables using SPSS software are summarized in the forms of correlation matrices in Tables 2 and 3.

Table 2: Correlation matrix for MF, Chl, N, Ca, and Fe in Lagos spinach

\begin{tabular}{llllll}
\hline & MF & Chl & N & CA & Fe \\
\hline MF & & & & & \\
Chl & -0.8522 & & & & \\
N & -0.9094 & 0.9907 & & & \\
Ca & -0.9312 & 0.9772 & 0.9865 & & \\
Fe & -0.9174 & 0.9869 & 0.9941 & 0.9928 & \\
\hline
\end{tabular}

Table 3: Correlation matrix for MF, Chl, N, Ca, and Fe in spinach

\begin{tabular}{llllll}
\hline & MF & Chl & N & CA & Fe \\
\hline MF & & & & & \\
$\mathrm{Chl}$ & -0.9135 & & & & \\
$\mathrm{~N}$ & -0.9634 & 0.9865 & & & \\
$\mathrm{Ca}$ & -0.9309 & 0.9931 & 0.9861 & & \\
$\mathrm{Fe}$ & -0.9772 & 0.9785 & 0.9960 & 0.9862 & \\
\hline
\end{tabular}

It was observed from Tables 2 and 3 that MF strongly and negatively correlated with chlorophyll, N, Ca, and $\mathrm{Fe}$ in the two investigated vegetables, suggesting that the magnetic field has inverse relationships with other examined variables. These relationships ascertain the patterns of damages or reductions caused by the magnetic field on the vegetables. This implies that the stronger the magnetic field intensity the less the concentrations of chlorophyll, $\mathrm{N}, \mathrm{Ca}$, and $\mathrm{Fe}$ in the vegetables.
Chlorophyll, N, Ca, and Fe were also observed to be strongly and positively correlated, indicating similar responses to the exposed magnetic field strengths.

\section{Conclusion}

The results from the regression analysis indicated that the four parameters were significantly correlated with the MF intensity. It was further observed that the effects of MF are stronger on spinach than Lagos spinach. 
Alabi et al. - Variations in the effects caused by magnetic field on chlorophyll, nitrogen, ...

This indicates that the effects are speciesdependent. The outcomes of the experiments indicated that the effects of magnetic fields on vegetable plants do not only depend on characteristics of field exposure such as intensity, but also are vegetable plant speciesdependent.

\section{References}

Adegbaju OD, Otunola GA and Afolayan AJ 2019 Influence of plant maturity on antimicrobial properties and toxicity of Celosia argentea. J. Biol. Sci. 19(4): 280289.

Blackman HF 1924 Field experiments in electro culture. J Agric. Sci. 14: 240-267.

Hart FX and Marino AA 1977 Energy flux along high voltage transmission lines. IEEE Trans. Biomed. Eng. 24(5): 493-495.

Muthuchelian K, Paliwal K and Gnanam A 1989 Influence of shading on net photosynthetic and transpiration rates, stomatal diffusive resistance, nitrate reductase, and biomass productivity of a woody legume tree species (Erythrina variegata Lam.). hoc. Proc. Indian Acad. Sci. (Plant Sci.) 99: 539-546.

Negishi Y, Hashimoto A, Tsushima M, Dobrota C, Yamashita $\mathrm{M}$ and Nakamura $\mathrm{T}$
1999 Growth of pea epicotyl in low magnetic field-implication for space research. Adv. Space Res. 23(12): 20292032.

Nyakane NE, Markus ED and Sedibe MM 2019 The effects of magnetic field on plants growth: a comprehensive review. Int. J. Food Eng. 5(1): 79-87.

Oladejo OF, Olukotun SF, Ogundele LT, Gbenu ST and Fakunle MA 2020 Radiological risk assessment of naturally occurring radioactive materials (NORMS) from selected quarry sites in Edo State, Southsouth, Nigeria. Environ. Earth Sci. 79(5): 93.

Reynolds JM 1997 An introduction to applied and environmental geophysics. John Wiley and Sons, England. pp. 118-121.

Tanasković I, Golobocanin D and Miljević N 2012 Multivariate statistical analysis of hydrochemical and radiological data of Serbian spa waters. J. Geochem. Explor. 112: 226-234.

Vian AE, Davies E, Gendraud M and Bonnet P 2016 Plant responses to high-frequency electromagnetic fields. BioMed Res. Int. 2016, Article ID 1830262, 13 pages. 